PRODUCTION

ENGINEERING ARCHIVES
2015,Vol. 7, No 2, pp 11-15

ISSN 2353-5156 (print version)

ISSN 2353-7779 (online version)

\footnotetext{
Article history: $\quad$ Received: 22.12.2014 Accepted: 27.03.2015 Online: 30.04.2015
}

\title{
Improving printing process in reflow and thick film technology through analysis and modeling of paste rheology
}

\author{
Eszter Horvath $^{1}$ \\ ${ }^{1}$ PhD., Budapest University of Technology and Economics Department of Vehicle Elements Vehicle-Structure Analysis, e-mail: \\ horvath@kge.bme.hu
}

\begin{abstract}
In the automotive industry the use of modern technology and provision of the highest quality product and related services is the most important element of rivalry between global corporations and motorcycles. In a competitive struggle for the recognition of its brand in the automotive market, global organizations continuously raise the requirements for quality management systems, so that the finished product meets all the standards in terms of safety and quality and satisfies the ever-growing needs of customers - present and future drivers and passengers of cars. ISO/TS 16949 quality management system is presented in this paper. The framework for customer specific requirement is illustrated as well as prevention of problems.
\end{abstract}

Key words - solder paste, thick film paste, printing process, constitutive model, rheological measurement, numerical method

\section{Introduction}

There are two common layer deposition methods in electronics technology. One of the most widely used techniques for depositing solder pastes is stencil printing (CLYDE, COOMBS, 2008), whereas the application of thick film pastes and adhesives is carried out by screen printing (TAPAN, 2003). This is a critical step in the mass assembly of electrical components (KRAMMER, 2014). As the electronic components, lead sizes and the contact surface areas (pad) on printed wiring boards or substrates continuously decrease, the size of stencil apertures became smaller which really challenges the printing process (MARKOVITS, BAUERNHUBER, MiKULA, 2013, HORVATH, 2008).
With the continuous advancement of the components, smaller pad sizes force paste suppliers to develop pastes with smaller metal powder particle sizes, micro alloys and new rheology modifier formulations to meet the requirements of the assembly. Since there are difficulties in miniaturising the components by bonding solder balls, the stencil printing of solder paste is still under investigation (DURAIRAJ ET. AL, 2008, SEO ET. AL, 2010).

Therefore, there is a growing need to describe the rheological behaviour of these pastes for optimising the printing settings. Analysis of the flow properties within the bulk of paste during printing are extremely difficult if not impossible to measure experimentally. However, numerical simulations can show the internal 
flow behaviour, adding an extra dimension to the understanding of the factors influencing print quality (FICZERE, BORBAS, TÖRÖK, 2013).

Most defects such as poor release, slumping and bridging originate from poor understanding of the flow properties and processing of solder pastes (ANDERSON, MARIA, KOLLI, 1995).

The development and use of computational models provides a way of understanding the details of the printing process that would be impossible or far too expensive to achieve through experiments alone.

The first efforts to achieve a theoretical description of the screen printing process were made by Riemer more than 20 years ago (RIEMER, 1998A, (RIEMER, 1998B). His mathematical models of the screenprinting process were based fundamentally on a Newtonian viscous fluid scraping model (TAYLOR, 1962). This model was extended by others (RIEDLER, 1983, JEONG, KIM, 1985). A mathematical model for the printing was proposed, in which the screen is modeled as a permeable membrane, and the entire region above and below the screen is flooded (WHITE, BREWARD, HOWELL, 2006). However, paste was handled as a Newtonian fluid. Recently, there were also investigations on optimization, using a statistical approach without any rheological analysis (YEN, FANG, LIN, 2011).

There were also many attempts in modeling solder paste behaviour. So far, power law models and cross model were typically applied to describe solder pastes (DURAIRAJ, RAMESH, MALLIK, 2009), however thixotropic material requires time dependent viscosity models (DurairaJ ET. AL., 2009). The Taguchi fuzzybased model was also developed to optimize the stencil printing process without using any rheological parameters (TSAI, 2011).

Apart from classical rheological bodies like elastic, plastic, viscous and its various combinations, a more general and effective theory was constructed. The theoretical background is always coupled with experimental tests to measure material constants that arise from the theory. Such experiments generally differ from conventional material tests because in most cases new properties (for example intrinsic material length) should be included. This approach was already successfully used in constitutive modeling problems in various other fields (MAUGIN, 1992, LUBLINER, 1990,
HOLZAPFEL, 2000, KRYNKE, BORKOWSKI, SELEJDAK, 2014). In the proposed research we plan to use such concepts in thick film and solder paste rheology.

The goal of our research is to define a constitutive model for these colloid materials and develop new measuring techniques to determine parameters to describe the paste rheology.

\section{Methodology}

Improvement of solder- and thick film paste modelling methods is essential and the development of suitable measuring methods to identify and obtain missing parameters for modeling is crucial. Pastes should be handled and used with an understanding of its characteristics and techniques, and technologies are involved to assure the optimum performance. Our hypothesis is that a new material model for these pastes enables the prediction of printing quality without long experimental setups. The selection and elaboration of the proper constitutive theory and rheological experiments, paste characterization for establishing the relationships between the pastes structure and flow behavior are necessary to enhance modelling. Elaboration of constitutive relations and measurement methods to determine the required material model parameters are essential in order to develop a new constitutive equation (material model) for colloidal dispersions (thick film and solder paste, flux) used in electronics technology. Creating numerical models is very important to simulate the technological processes of colloidal materials as they are utilized in reflow and thick film technology. Development of experimental measurement methods to determine the conditions and range of validity of the new material model - focusing on real circumstances- are very rare and expensive but essential.

Firstly, a continuum mechanical model should be formed including a general constitutive relation collecting all the important physical effects to the problem. After peer reviewing the latest results of thick film and solder paste manufacturers and researchers, rheological tests measurements of commercially available solder paste and thick film paste will be executed in this phase. Due to the time factor involved in terms of paste materials phenomenon, dynamic mechanical measurements are needed for the characterization. For 
the viscosity tests, a highly accurate rheometer system will be used (with a cone - plate or parallel plate measuring geometry). The thixotropic breakdown of solder paste by shearing will be examined quantitatively. The value of viscosity depends on several physical parameters e.g. shear rate, temperature and - due to thixotropy behavior - the acting time of stress too. Since printing processes are generally carried out at room temperature in the production line, our experiment will also be performed at this temperature.

After thorough analysis and studies of these colloidal substances the most appropriate model will be determined.

Solder and thick film pastes are multiphase systems. These pastes can produce slip-effects when flowing between smooth solid boundaries. Experiments and a theoretical investigation will be performed to study and determine the significance of this phenomenon. Since rheometers with smooth measuring geometries such as smooth parallel plate and smooth cone andplate measuring geometries are more sensitive to wallslip effects, the use of rough plates will be considered. If required, the viscosity and oscillatory rheological measurements will be performed using both serrated and smooth parallel plate geometries.

By development and realization of a suitable measuring method to quantify these small forces, the effect of surface roughness on wall-slip formation in the rheological measurements of pastes will be investigated. Verification will also be performed, aiming to prove the implementation of the measuring technique is correct; so the model parameters fitted to measurement data provide reliable results.

The aim of these experiments is to investigate how slip can be reduced or controlled by the use of rough surfaces.

The main criteria for pastes will be derived from the experimental studies. Based on the results of the evaluated rheological measurements, the designation of the most appropriate model with proper parameters for the solder and thick film paste in a given environment will be carried out. The first and most important step for the numerical simulation is to determine the mathematical description of the solder and thick film paste behavior in the function of shear rate and estimate the shear thinning property of non-Newtonian materials. The viscoelastic effects will be considered in the model if the preliminary studies justify it. The developed model will allow us to create highly accurate simulation and estimation of solder and thick film paste behavior during the printing process.

Numerical modeling of the solder and thick film materials allows prediction of the entire technological process. The finite element or finite volume method can be a suitable tool to handle the deformation process of pastes and the viscosity issues can also be taken into account. It is also useful to quantify the mixing phenomenon that occurs inside the pastes. These results help to understand the behavior of the materials during the manufacturing process. The development of a numerical model can be carried out using commercial software products. The mainstream finite element software solutions contain the opportunity to develop user defined material models. Taking advantage of this, a powerful method is available to perform analyses and post processing the computed data.

In order to get reliable results from the numerical analysis, it is necessary to identify the parameters of the material models by well-established measurements. The experimental method must be general enough to consider all of the main issues, however, as simple as possible at the same time. At first, the available measurement methods have to be collected and applied, and these methods needs further development to gain additional information about the materials. It is also important to examine how wide the range of validity is, and under what circumstances the material has to be examined. The velocities that occur during the process can be an important issue which has vital importance to the material behavior.

After the identification of the material parameters, the next step must be the numerical representation of a suitable test example. If the computed and the measured results are in good agreement with each other, the numerical technique can be considered as a reliable approximation of real applications. With the proper material parameters and numerical solution technique at hand, it is possible to handle custom applications in context of the technologies where solder materials and thick film pastes are used. 


\section{Experimental design and methods}

Dynamic rheological test measurements of commercially available solder paste and thick film paste will be conducted using a controlled rate rheometer. For the tests, a highly accurate rheometer system will be used operating with cone - plate or parallel plate geometry. Constant torque will be applied to the sample and measure the strain or rate of strain generated in the sample.

The distance of the parallel plates will be set according to the largest particle diameter in order to avoid any unexpected effect, because particles can get stuck or deformed.

An oscillatory amplitude sweep test will be carried out to characterise the viscous and elastic properties of the pastes. Using this method, the linear viscoelastic region of the pastes can be determined. During the test, sinusoidal varying stress will be set with a constant frequency to the sample and the generated sinusoidal varying strain will be measured.

The ratio of the applied shear stress to the maximum strain indicates the resistance to the deformation for material.

The thixotropic breakdown of solder paste by shear will be examined quantitatively. The thixotropy measurement will be carried out by creep - recovery test. The behaviour of the pastes during the printing process can be divided into three steps: pre-printing, printing and post-printing. The paste is in rest throughout the pre-printing step, although pre-stirring and flooding can cause a stressed state. Therefore, before starting the test the sample has to rest for about 1 minute. To simulate the pre-printing step, a low shear rate will be used, whereas a high shear rate has to be set for printing step. During post-printing step, the shear rate will decrease back to the original value for a longer interval, so the pastes will recover and get back their structures. Since printing processes generally carried out at room temperature in the production line, our experiment will also be performed at this temperature with the temperature being controlled by a Peltier plate system. The reproducibility of the experimental results will be confirmed by doing repeats for measurements; the results deviation on average will be calculated.

After determining the rheological parameters, setting-up the structural kinetic model of the selected pastes will be executed. Depending on the rheological model, some parameters might be fitted to the experiments. Model verification will be performed, aiming to highlight whether the model parameters fitted to experimental results are suitable for modelling.

The theoretical order of experiments is as follows:

1. Viscosity shear rate sweep test will be performed to characterize the shear thinning behaviour of pastes.

2. The thixotropic breakdown of solder paste by shear will be examined quantitatively by creep recovery test.

3. The determination of rheological parameters based on the experiments.

4. Development and realization of a suitable measuring method to quantify small forces of wall-slip effect.

5. Setting-up the structural kinetic model of tested pastes.

6. Development of experimental measurement method to determine the conditions and range of validity of the new material model.

7. Model verification will be performed, aiming to highlight whether the model parameters fitted to experimental results can meet usability for complex modelling of the printing process.

\section{Summary}

We expect that our work will contribute to a more efficient production of electronic circuits and devices, and we can elaborate a new material model and measuring technique to describe the mechanisms taking place during the printing process.

We expect that we can develop a more suitable material model for solder- and thick film pastes, which takes into account the time dependent viscous behaviour.

We plan to develop and realize an adequate measurement method to determine the required model parameters.

Characterisation of solder- and thick film pastes is going to be achieved by rheological measurements and experiments.

We also expect that we can implement the new material model in computational simulation and enable to set printing parameters in a simpler and more efficient way. 
We expect that due to the description and implementation of the rheological behaviour, we can improve the real printing process based on our studies.

Paste printing is a crucial sequence of reflow technology which is a generally cost-effective manner of production in electronic circuits. Therefore, the rheological behaviour of solder- and thick film pastes has to be deeply discovered and understood. An essential advantage of using a precise material model can also explore the changes in microstructure of pastes during shearing, thus the printing parameter could be optimized achieving the best quality of deposits.

\section{References}

1. Anderson R., Maria FG., Kolli V.G. 1995. Solder paste rheology and fine pitch slump. JSMT 1995:12-8.

2. Clyde F. CoOmbs, JR. 2008. Printed Circuits Handbook, McGraw-Hill, USA.

3. DURAIRAJ R., RAMESH S., MALLIK S. 2009. Rheological characterisation and printing performance of $\mathrm{Sn} / \mathrm{Ag} / \mathrm{Cu}$ solder pastes, Materials and Design 30 3812-3818.

4. Durairaj, R., MALliK, S. AND EKERE, N.N. 2008. Solder paste characterisation: towards the development of quality control tool, Soldering \& Surface Mount Technology, Vol. 20, No. 3, pp. 34-40.

5. Durairaj, S., MalliK, A., Seman, A., Marks, N.N. EKERE 2009. Rheological characterisation of solder pastes and isotropic conductive adhesives used for flipchip assembly, Journal of Materials Processing Technology 209, 3923-3930.

6. FiCZere P., BorBÁs L.., TÖRÖK Á. 2013. Economical Investigation Of Rapid Prototyping, International Journal For Traffic And Transport Engineering 3:(3):344-350., Doi: 10.7708/Ijtte.2013.3(3).09.

7. Holzapfel, G. 2000. Nonlinear Solid Mechanics: A Continuum Approach for Engineering Wiley; Cichester.

8. HORVÁTH E. 2008. Embedded Thick-Film Resistors Applied in Low Temperature Co-fired Ceramic Circuit Substrates, Periodica Polytechnica: Electrical Engineering 52: (1-2) pp. 45-57.

9. JeOng J., KIM M., 1985. Slow viscous flow due to sliding of a semi-infinite plate over a plane, Journal of Physics Society, 54, 1789-1799.

10. Krammer O. 2014. Finite Volume Modelling of Stencil Printing Process, 20th International Symposium for De- sign and Technology in Electronic Packaging (SIITME) pp. 79-82.

11. Krynke M., BorKowsKi S., SELEJDAK J. 2014. Analysis of influence of bearing clearance on the static carrying capacity of multi-row slewing bearings, Periodica Polytechnika Transport Engineering, 42(1):43-48, 2014, doi: 10.3311/PPtr.7261Lubliner, J. (1990): Plasticity Theory, Macmillan, New York.

12. Markovits T., Bauernhuber A., Mikula P. 2013. Study on the transparency of polymer materials in case of Nd:YAG laser radiation, Periodica Polytechnika Transportation Engineering, 41(2):149-154, doi: 10.3311/PPtr.7117.

13. Maugin G.A. 1992. The Thermodynamics of Plasticity and Fracture, Cambridge Univ. Press. Cambridge.

14. RIEDLER J., 1983. Viscous flow in corner regions with a moving wall and leakage of fluid, Acta Mechanica, 48, 95-102.

15. RIEMER D.E., 1988A. Analytical model of the screen printing process: part 1, Solid State Technology,8, 107111.

16. RiEMER D.E., 1988B. Analytical model of the screen printing process: part 2, Solid State Technology, 9, 8590.

17. SeO, W.S., Min, B.W., KIM, J.H., LEE, N.K. AND KIM, J.B. 2010. An analysis of screen printing using solder paste, J. Microelectron. Packag. Soc., Vol. 17 No. 1, pp. 47-53.

18. TAPAN G. 2003. Handbook of Thick and Thin-Film Hybrid Microelectronics. Hoboken, N.J: WileyInterscience.

19. TAYLOR G.I., 1962. On scraping viscous fluid from a plane surface, Miszallangen Angewandten Mechanik, 313-315.

20. TSAI T.-N. 2011. Improving the fine-pitch stencil printing capability using the Taguchi method and Taguchi fuzzy-based model, Robotics and Computer-Integrated Manufacturing 27808-817.

21. White G.S., Breward C.J.W., Howell P.D. 2006. A model for the screen-printing of Newtonian fluids, Journal of Engineering Mathematics, 54, 49-70.

22. YEN Y.-T., FANG T.-H., LIN Y.-C. 2011. Optimization of screen-printing parameters of SN9000 ink for pinholes using Taguchi method in chip on film packaging, Robotics and Computer-Integrated Manufacturing 27 531-537. 